\title{
Longitudinal Associations Between Trait Neuroticism and Negative Daily Experiences in Adolescence
}

\author{
Jeroen Borghuis \\ Tilburg University \\ Klaas Sijtsma \\ Tilburg University \\ Wim H. J. Meeus \\ Utrecht University and Tilburg University
}

\author{
Wiebke Bleidorn \\ University of California, Davis \\ Susan Branje \\ Utrecht University
}

Jaap J. A. Denissen

Tilburg University

\begin{abstract}
It is well established that trait neuroticism bears strong links with negative affect and interpersonal problems. The goal of this study was to examine the longitudinal associations between neuroticism and daily experiences of negative affect and interpersonal problems during the developmentally important period of adolescence. Dutch adolescents and their best friends $(N=1,046)$ completed up to 6 yearly personality trait questionnaires and up to 15 between-year assessment bursts between the ages 13 and 18 . During each assessment burst, participants reported on 5 consecutive days about their experiences of negative affect and interpersonal conflict with their mother and their best friend. We estimated a series of multilevel random-intercept cross-lagged panel models to differentiate covariance at the level of constant between-person differences from dynamic processes that occurred within persons. At the level of constant between-person differences, higher neuroticism was associated with more negative daily experiences. At the within-person level, yearly changes in neuroticism were bidirectionally and positively associated with yearly changes in daily negative affect. The most parsimonious, best fitting models did not contain a random intercept for daily conflict with friend and adolescents' contingency between daily experiences of conflict with mother and negative affect. Rank-order differences in these variables were positively associated with subsequent within-person changes in neuroticism. We discuss these results with regard to endogenous versus dynamic theories of personality development and the value of using a differentiated statistical approach.
\end{abstract}

Keywords: adolescence, experience sampling, negative affect, neuroticism, relationship conflict

Supplemental materials: http://dx.doi.org/10.1037/pspp0000233.supp

Neuroticism represents a continuum of individual differences, with low levels representing emotional stability and eventemperedness, and high levels representing negative emotionality (John, Naumann, \& Soto, 2008). High levels of neuroticism have been related to undesirable life outcomes, including poor mental and physical health (Lahey, 2009; Ormel, Jeronimus, et al., 2013), negative affect (Ching et al., 2014; Costa \& McCrae, 1980; Mroczek \& Almeida, 2004), and interpersonal problems (Karney \&
Editor's Note. R. Chris Fraley served as the action editor for this article.-MLC

This article was published Online First January 24, 2019.

Jeroen Borghuis, Department of Developmental Psychology, Tilburg University; Wiebke Bleidorn, Department of Psychology, University of California, Davis; Klaas Sijtsma, Department of Methodology and Statistics, Tilburg University; Susan Branje, Research Centre Adolescent Development, Utrecht University; Wim H. J. Meeus, Research Centre Adolescent Development, Utrecht University, and Department of Developmental Psychology, Tilburg University; Jaap J. A. Denissen, Department of Developmental Psychology, Tilburg University.
RADAR has been financially supported by main grants from the Netherlands Organisation for Scientific Research (GB-MAGW 480-03-005, GB-MAGW 480-08-006, GB-MAGW 481-08-014), from a grant to the Consortium Individual Development (Grant 024.001.003) from the Netherlands Organization for Scientific Research, from grants by Stichting Achmea Slachtoffer en Samenleving (SASS), and various other grants from the Netherlands Organisation for Scientific Research, the Vrije Universiteit University Amsterdam and Utrecht University.

Mplus output files, which contain model specifications and parameter estimates, can be found at https://osf.io/dsnvc.

Correspondence concerning this article should be addressed to Jeroen Borghuis, who is now at Statistics Netherlands (CBS), P.O. Box 24500, 2490 HA The Hague, the Netherlands. E-mail: j.borghuis1@gmail.com 
Bradbury, 1995; Kelly \& Conley, 1987; Lopes, Salovey, \& Straus, 2003). In addition, neuroticism has been associated with substantial costs for both the individual and society (Cuijpers et al., 2010), so it is not surprising that many individuals desire to be less neurotic (Hudson \& Fraley, 2016). Longitudinal research has identified adolescence as a sensitive period during which individual differences in neuroticism become increasingly settled (Bleidorn \& Hopwood, in press; Borghuis et al., 2017; Briley \& Tucker-Drob, 2014; Roberts \& DelVecchio, 2000). However, little is known about the factors and mechanisms underlying the development of neuroticism during this life stage. Given the relevance of neuroticism for both individual and society, an interesting question is what predicts changes in neuroticism?

Previous research suggested that, even though most youth experience few difficulties (Arnett, 1999), prevalence rates of mood disorders and interpersonal problems peak during adolescence (e.g., Hadiwijaya, Klimstra, Vermunt, Branje, \& Meeus, 2017; Maciejewski, van Lier, Branje, Meeus, \& Koot, 2017). This finding led some researchers to theorize that increases in adolescents' neuroticism can be traced back to increasing problems in daily life (Göllner et al., 2017; Soto, 2016). Therefore, neuroticism may not only have an influence on affective and interpersonal problems that typically occur during adolescence, but these problems may also influence adolescents' level of neuroticism.

The present study aimed to gain a better understanding of the longitudinal associations between neuroticism and daily experiences of negative affect and interpersonal problems during adolescence. We tested whether changes in neuroticism predict changes in negative daily experiences, whether changes in negative daily experiences predict changes in neuroticism, or both. To address these questions, we used multiwave data collected as part of a 5-year measurement burst study (i.e., 6 yearly personality measurements combined with intermitted daily diary assessments administered between age 13 and 18). We used multilevel structural equation models to differentiate constant (i.e., time-invariant, enduring) between-person differences from changes that occurred within persons.

\section{Theoretical Perspectives on the Associations Between Neuroticism and Negative Daily Experiences}

Two broad theoretical traditions have made contrasting predictions about the longitudinal relation between neuroticism and negative daily experiences. These traditions focused on personality development in adult populations, but their propositions can be generalized to adolescents. Endogenous personality theories, such as five factor theory (McCrae \& Costa, 2008; McCrae \& Sutin, 2018), posit that personality traits have a unidirectional influence on people's daily psychological experiences. According to this perspective, personality traits set in motion downstream processes (emotional, behavioral, cognitive, and social) that, in interaction with external influences, produce specific experiences. As such, endogenous personality theories would predict that increases in neuroticism lead to subsequent increases in negative affect and relationship conflict. Over time, these unidirectional influences may accumulate and manifest as stable between-person associations. Furthermore, endogenous theories predict that daily experiences have no or only a negligible influence on broad personality traits such as neuroticism (McCrae \& Sutin, 2018). As such, endogenous theories would predict that changes in daily experiences of negative affect and conflict are unrelated to subsequent changes in neuroticism.

Contrary to endogenous accounts, dynamic personality theories posit that people's personality traits and their daily experiences continuously influence each other over time (Endler \& Parker, 1992; Magnusson, 1990; Roberts, Wood, \& Caspi, 2008). A key tenet of dynamic personality theories is that personality trait changes unfold gradually through the accumulation of daily experiences and through people's responses to these experiences (Baumert et al., 2017; Geukes et al., 2017; Roberts \& Jackson, 2008; Wrzus \& Roberts, 2017). More specifically, dynamic theories posit that personality trait changes are driven by experiences that influence state levels (i.e., momentary thoughts, feelings, and behaviors) and/or state contingencies (i.e., how much different states depend on each other) that are relevant to a personality trait (see also Buss \& Craik, 1983; Fleeson \& Jolley, 2006). For example, adolescents may increase in neuroticism because they repeatedly experience daily relationships conflicts or anxious and nervous states. In addition, their neuroticism level may increase because they become increasingly upset during conflicts; that is, because their affective states increasingly depend on their conflict experiences. During development, these dynamic transactions may partly crystalize as stable between-person associations between neuroticism and state levels/contingencies.

To summarize, endogenous and dynamic personality theories agree that changes in neuroticism are likely associated with subsequent changes in negative daily experiences, and that constant between-person differences in neuroticism might be associated with constant between-person differences in negative daily experiences. However, whereas endogenous theories posit that daily experiences are unrelated to subsequent changes in neuroticism, dynamic theories predict that changes in daily experiences are positively associated with subsequent changes in neuroticism.

\section{Previous Research on the Associations Between Neuroticism and Negative Daily Experiences}

Consistent with both endogenous and dynamic theories, previous research has suggested several processes through which neuroticism may influence people's daily experiences of negative affect and interpersonal problems. For example, compared with emotionally stable individuals, neurotic individuals pay more attention to negative and threatening stimuli and recollect them better (Ormel, Bastiaansen, et al., 2013), are more likely to interpret ambiguous social cues as signs of rejection (Finn, Mitte, \& Neyer, 2013), have more hostile and stronger affective reactions to stress (Gunthert, Cohen, \& Armeli, 1999; Leger, Charles, Turiano, \& Almeida, 2016; Mroczek \& Almeida, 2004; Suls \& Martin, 2005; Suls, Martin, \& David, 1998), and experience negative affective reactions that are more likely to spill over to other situations (Suls \& Martin, 2005). Note, however, that most of these results were drawn from cross-sectional studies, which are not suited to address questions concerning the directionality of effects.

Evidence regarding the question whether negative daily experiences can affect neuroticism during adolescence is mixed. Some studies suggested that experiences of daily hassles (Vollrath, 2000) and stressful life events, such as unemployment and divorce, are related to changes in neuroticism (Jeronimus, Ormel, Aleman, 
Penninx, \& Riese, 2013; Jeronimus, Riese, Sanderman, \& Ormel, 2014; Kandler, Bleidorn, Riemann, Angleitner, \& Spinath, 2012; Riese et al., 2014). However, other studies found no evidence that such experiences are related to changes in neuroticism (Allemand, Hill, \& Lehmann, 2015; Denissen, Luhmann, Chung, \& Bleidorn, 2018; Specht, Egloff, \& Schmukle, 2011; for a review, see Bleidorn, Hopwood, \& Lucas, 2018). Similarly, studies yielded mixed and inconclusive results about the effect of interpersonal problems with peers (cf. Asendorpf \& Wilpers, 1998; Mund \& Neyer, 2014; for reviews, see Wrzus \& Neyer, 2016; Wrzus, Zimmermann, Mund, \& Neyer, 2016) and the experience of a depression (Ormel, Jeronimus, et al., 2013) on neuroticism.

Notably, these findings reflect indirect evidence with respect to the present research question. First, most studies were based on samples of adults rather than adolescents (for an exception, see Sturaro, Denissen, Van Aken, \& Asendorpf, 2008). Second, most studies used general, retrospective reports about the occurrence of stress, conflicts, or negative life events, administered simultaneously with personality questionnaires. Only few studies used daily diary or experience sampling measures to assess actual daily experiences in people's everyday lives (for an exception, see Wrzus, Luong, Wagner, \& Riediger, 2017; see below). Third, although theories of human development usually refer to development that occurs at the within-person level (Baltes \& Nesselroade, 1979), most studies examined longitudinal associations between neuroticism and experiences at the between-person level (for exceptions, see Allemand et al., 2015; Denissen et al., 2018; Mund \& Neyer, 2014). The between-person level focuses on whether individual differences in experience predict subsequent rank-order changes (i.e., changes of individuals' relative standing) on a personality trait and/or vice versa. This may be problematic, because simulation studies suggest that associations found at the between-person level are not always a good representation of the processes that operated at the within-person level (Berry \& Willoughby, 2017; Hamaker, Kuiper, \& Grasman, 2015).

A more direct and reliable test of the prediction of dynamic personality theories that changes in state levels and state contingencies influence personality traits requires a measurement burst design in which participants report repeatedly about their momentary or daily experiences over a longer period. Using a measurement burst design enables researchers to empirically estimate for each individual the relation between one state (e.g., relationship conflict) and another state (e.g., negative affect), and to associate state levels and state contingencies with changes in personality traits. In addition, gaining a better understanding of the relation between neuroticism and daily experiences requires statistical approaches that differentiate covariance at the level of constant between-person differences (Anusic \& Schimmack, 2016; Fraley \& Roberts, 2005; Roberts, 2018) from dynamic processes that occurred within persons.

To our knowledge, only one study used a measurement burst design and within-person modeling to examine the longitudinal relationships between personality traits, state levels, and state contingencies. Wrzus et al. (2017) examined the links between affective experiences and neuroticism using 6-year longitudinal data from more than 500 German participants (14 to 86 years old) who reported on both their trait neuroticism and their daily negative affect and hassles (i.e., unpleasant experiences or thoughts) across three assessment waves. This study found no evidence that within-person changes in neuroticism predicted subsequent within- person changes in participants' daily experiences of negative affect, their daily experiences of hassles, or their affective reactivity to daily hassles (i.e., the extent to which hassles increased their momentary negative affect), nor vice versa. However, Wrzus and colleagues did find evidence that within-person increases in negative affect and hassle reactivity were concurrently associated with rank-order change in neuroticism. Specifically, across two 3-year assessment intervals, they consistently found that latent changes in negative affect and hassle reactivity between two assessments predicted rank-order differences in neuroticism at the later assessment, controlling for rank-order differences in neuroticism at the prior assessment. This study provides initial evidence for dynamic developmental processes between daily experiences and change in broad personality traits. However, more evidence is needed to test whether these results replicate and generalize to other developmental periods and experiences.

\section{The Present Study}

The purpose of this measurement burst study was to examine the longitudinal associations between neuroticism and daily experiences of negative affect (operationalized as feelings of anxiety, sadness, and anger) and interpersonal problems with parents and peers (operationalized as conflicts with mother and best friend) between age 13 and 18. We focused on adolescence, because this period seemed particularly suited to examine the longitudinal relationship between neuroticism and negative daily experiences. After all, adolescents tend to experience more turmoil (Arnett, 1999) and undergo more pronounced changes in their level of neuroticism than adults (Borghuis et al., 2017; Roberts \& DelVecchio, 2000; Soto \& Tackett, 2015). Hence, transactional processes between neuroticism and negative daily experiences should be more salient during adolescence than during later life stages. At later ages, personality traits might have stabilized to such an extent that one would need very large samples to detect presumably small transactional effects (Adachi \& Willoughby, 2015).

Furthermore, we focused on interpersonal problems with both parents and peers, because conflicts that characterize these relationships may have different implications for adolescents' neuroticism development. Conflicts with parents may occur more frequently (Van Doorn, Branje, Hox, \& Meeus, 2009) and may arise from adolescents' need for separation-individuation from their parents (Koepke \& Denissen, 2012). Conflicts with peers may arise from competition for access to important resources, such as social status (Ellis et al., 2012; Hawley, Little, \& Card, 2007), and may pose a threat of social exclusion.

We used random-intercept cross-lagged panel modeling (Hamaker et al., 2015) to differentiate covariance at the level of constant between-person differences from dynamic processes that occurred within persons. We applied this technique to examine associations between neuroticism and adolescents' daily experiences of negative affect (Model 1), interpersonal problems with their mother (Model 2), and interpersonal problems with their best friend (Model 3). In addition, we examined the associations between neuroticism and adolescents' affective reactivity to interpersonal problems with their mother (Model 4) and their best friend (Model 5). We operationalized affective reactivity as the degree to which adolescents' level of daily negative affect was 
contingent on their level of daily relationship conflict (Denissen \& Penke, 2008; Wrzus et al., 2017).

In our interpretation of the results, we will pay special attention to the cross-lagged effects of negative daily experiences on neuroticism. Positive within-person effects of negative daily experiences on neuroticism are consistent with dynamic perspectives, but inconsistent with endogenous perspectives. Positive cross-lagged effects of neuroticism on negative daily experiences and positive associations at the level of constant between-person differences are consistent with dynamic perspectives as well as with endogenous perspectives. Finally, because our participants underwent relatively rapid and profound biological, psychological, and social changes during the study period (Blakemore, 2008; Casey, Jones, \& Hare, 2008; Koepke \& Denissen, 2012; Weisfeld, 1999), we explored whether the magnitude of the longitudinal effects changed during adolescence.

\section{Method}

The RADAR study has been approved by the Medical Ethical Testing Committee of the Utrecht University Medical Centre (protocol number $05-159 / \mathrm{K}$; "RADAR: Research on Adolescent Development and Relationships").

\section{Research Design and Procedure}

Data came from the RADAR-Young (Research on Adolescent Development and Relationships-Younger cohort) study (Van Lier et al., 2011), which is an ongoing prospective cohort-sequential study of Dutch-speaking families in the Netherlands. The study includes a Dutch population sample of target adolescents $(n=$ 497) and a Dutch-Moroccan sample of target adolescents $(n=$ 165). In addition, the study includes data from best friends, parents/caregivers, and one sibling of the target adolescents from the Dutch population sample. For the present study, we used selfreports from the target adolescents and their best friends between 2005 (the first yearly trait measurement) and 2010 (the sixth yearly trait measurement). External funding for the Dutch-Moroccan subsample ran out a year earlier, so only five waves were collected in this group. In each wave, target adolescents could nominate one best friend, which could be a different friend in each wave. For target adolescents from the Dutch population sample, the nominated friend was invited to participate in the study. We modelled each participating friend as a unique participant. Participants were recruited from randomly selected elementary schools in the western and central regions of the Netherlands. Participants received written information about the aim of the study and parents provided informed consent of all participating family members. During the study, target adolescents from the Dutch-Moroccan sample showed a higher dropout rate $37 \%$ in the first five waves compared with $15 \%$ in the Dutch population sample). We included the Dutch-Moroccan sample in the present study to increase the size and diversity of our sample.

RADAR participants participated in yearly home interviews and in online daily diary assessments. We measured participants' personality traits during the yearly interviews, which took place in February or March. We measured negative affect and interpersonal problems during three bursts of daily assessments that took place in-between the yearly trait measurements, in June, September, and
December. Each between-year assessment burst lasted five consecutive days (from Monday to Friday), adding up to 15 daily assessments per year, totaling a maximum of 75 daily assessments per participant across the study period. The assessment bursts always covered the weekdays of a normal school week. At approximately 5:30 p.m., participants were invited via e-mail to participate in the daily assessment. Participating families received $€ 100$ for each home visit, which lasted approximately $2.5 \mathrm{~h}$. Adolescents received an additional $€ 10$ for each between-year assessment burst they completed.

Some previous studies have also used the RADAR data to study personality traits (Borghuis et al., 2017; Creemers et al., 2015; Evans et al., 2016; Hawk et al., 2013; Mercer, Keijsers, Crocetti, Branje, \& Meeus, 2016; Salemink, van Lier, Meeus, Raaijmakers, \& Wiers, 2015; Yu, Branje, Keijsers, Koot, \& Meeus, 2013). However, none of these studies have examined associations between personality traits and daily affective or interpersonal experiences during adolescence.

\section{Participants and Missing Data}

Our final sample included $N=1,046$ adolescents, who were 13.1 years old $(S D=0.65)$ at the first trait measurement. Of these participants, $49 \%$ were best friends, $54 \%$ were female, $8 \%$ reported having a Moroccan ethnic identity, and 5\% reported having another non-Dutch ethnic identity. Among the 534 target adolescents, $22 \%$ did not have a friend who participated in RADAR and met our inclusion criterion, $62 \%$ had one friend, $14 \%$ had two friends, and $2 \%$ had three participating friends who met our study inclusion criterion.

Initially, our data contained 1,733 cases (i.e., 662 target adolescents and 1,071 friends). Because of early dropout or friendship dissolutions, some cases (mostly friends) had missing data on our study variables across the entire study period. For example, 201 adolescents did not participate in any of the yearly neuroticism measurements, and 389 adolescents did not participate in any of the assessment bursts. To reduce the proportion of missing data and to increase the covariance coverage between temporally widely spaced assessments, we included only target adolescents and friends who completed at least one yearly trait measurement and at least 15 daily negative affect or conflict assessments.

Based on teacher ratings of children's externalizing behavior, the RADAR study oversampled adolescents who were at risk of developing delinquent behaviors (Keijsers et al., 2012; Neumann, van Lier, Frijns, Meeus, \& Koot, 2011). In our final sample, 209 adolescents (39\% of the target adolescents; $13 \%$ belonged to the Dutch-Moroccan sample) were classified "at risk." Compared with adolescents who were not at risk, at risk target adolescents reported more negative affect, $t(358.88)=3.23, p=.001, d=0.29$ and more conflict with their mother, $t(380.94)=3.74, p<.001, d=$ 0.33 during the first three assessment bursts. Despite the oversampling of at risk adolescents, on average our participants and their parents had a higher socioeconomic status than the general Dutch population (Keijsers et al., 2012; Neumann et al., 2011; Van Lier et al., 2011).

There were 237 adolescents (74\% friends) who participated in the first trait measurement wave but not in the last one. These dropouts did not significantly differ from continuing participants (i.e., adolescents who participated in both the first and the last trait 
measurement; $n=622^{1} ; 25 \%$ friends) with regard to their Big Five scores at the first trait measurement or their average level of conflict and negative affect across the first three assessment bursts. Table 1 provides an overview of the number of available reports for neuroticism, negative affect, and relationship conflict.

\section{Measures}

Neuroticism. Neuroticism was measured using the shortened Dutch version of Goldberg's Big Five questionnaire (Vermulst \& Gerris, 2005), using six adjectives (e.g., "worried"). Participants indicated on a Likert scale ranging from 1 (completely untrue) to 7 (completely true) to what extent the adjectives described their personality. Previous research using data from this sample showed that this measure demonstrated longitudinal scalar measurement invariance (i.e., consistent item loadings and intercepts) across six yearly measurements, indicating that participants used and interpreted this scale in a similar way from age 13 to age 18 (Borghuis et al., 2017). In the present study, coefficient $\alpha$ (Cronbach, 1951) of the six neuroticism measurements ranged from .80 to .87 . An analysis of within- and between-person variance (using the statsBy function of the psych package in R; Revelle, 2017) indicated that the ICC1 (intraclass correlation coefficient) of the random intercept of neuroticism (see Statistical Analysis) was .59. Hence, 59\% of the total variance of neuroticism across the six measurements was attributable to constant between-person differences in neuroticism, and the remaining $41 \%$ was because of yearly within-person fluctuations.

Daily negative affect. On each day of the assessment bursts, participants rated their level of negative affect using the Anger, Anxiety, and Sadness subscales of the Daily Mood Device (Hoeksma et al., 2000). Adolescents were asked in the late afternoon to rate the intensity of their emotional experiences of that particular day ("Today I feel ...") using 9-point Likert scales (e.g., from $1=$ not down to $9=$ down; from $1=$ not afraid to $9=$ afraid). We measured adolescents' daily negative affect by averaging their scores on the following nine adjectives: "angry," "cross," "short-tempered," "sad," "down," "dreary," "afraid," "anxious," and "worried." Coefficient $\alpha$ per assessment day was high, ranging from .89 to $.97(\bar{\alpha}=.95)$ across the 75 daily assessments. Previous research has established longitudinal scalar measurement invariance of this measure across days and annual assessment waves during adolescence (Maciejewski et al., 2017). ICC2 coefficients of the year-specific (Level 2) random intercepts of this measure (see Statistical Analysis) ranged from .93 to .96 across the five study years, indicating that participants differed reliably from each other in their yearly average level of negative affect. The ICC1 coefficient of the Level 3 random intercept of the five Level 2 random intercepts was .69, which indicates that $69 \%$ of the variance across the five yearly mean levels of negative affect was attributable to between-person differences and $31 \%$ was attributable to yearly within-person fluctuations.

Daily relationship conflict. During assessment bursts, participants reported the extent to which they had experienced relationship conflict with their mother and their best friend, using two items of the Negative Interaction Scale of the Network of Relationship Inventory (NRI; Furman \& Buhrmester, 1985). Participants responded on a 7 -point Likert scale $(1=$ not at all, $7=$ very much) to the questions "Did you and your friend/mother get on each other's nerves today?" and "Did you and your friend/mother quarrel today?" For conflict with mother, coefficient $\alpha$ ranged from .79 to $.92(\bar{\alpha}=.87)$ across the 75 daily assessments. For conflict with friend, $\alpha$ ranged from .59 to $.89(\bar{\alpha}=.78)$ across the 75 daily assessments. Agreement between the target adolescents' and friends' self-reported level of daily conflict with each other was moderate (on average, $r=.30$ across the 75 daily assessments). Previous research established longitudinal metric invariance (i.e., consistent item loadings) across adolescence for this measure (Crocetti, Branje, Rubini, Koot, \& Meeus, 2017). Note that the subsample of best friends did not report daily relationship conflicts with their mother; all other measures included in this study were collected among both target adolescents and best friends. ICC 2 coefficients of the yearly Level 2 random intercepts ranged from .84 to .88 for conflict with mother and from .79 to .85 for conflict with friend. The ICC1 coefficients of the Level 3 random intercepts were .56 (conflict with mother) and .49 (conflict with friend).

\section{Statistical Analysis}

We analyzed the longitudinal associations between neuroticism and daily experiences using multilevel structural equation modeling (MSEM; Preacher, Zyphur, \& Zhang, 2010) in Mplus Version 7 (Muthén \& Muthén, 1998-2012), by means of the MplusAutomation package (Hallquist \& Wiley, 2018) in R (R Core Team, 2016, Version 3.4.4). The multilevel approach allowed us to account for the nested structure of the yearly measurement burst data, with up to 15 daily reports varying each year within and between persons. $^{2}$ To also account for the dependency between friends' observations, we used the "complex twolevel" (Models 1 and 3) and "complex twolevel random" (Model 5) functions of Mplus, in conjunction with a cluster variable identifying friendship dyads.

We used MLR estimation in all models, which estimated model parameters using maximum likelihood and computed SEs that were robust to nonnormality and nonindependence of observations. By default, Mplus handles missing data based on variables that are included in the analysis model. To improve the handling of missing data, we also specified auxiliary variables. Auxiliary variables are variables that are not part of the analysis model but improve the estimation of missing data provided they were missing at random. The auxiliary variables that we included were gender, type of respondent (target adolescent vs. friend), subsample (Dutch population vs. Dutch-Moroccan), risk status for developing delinquent behavior, all yearly extraversion, agreeableness, conscientiousness, and openness variables, and those daily conflict with mother/conflict with friend/negative affect variables that were not part of a particular analysis model.

\footnotetext{
${ }^{1}$ There were 187 adolescents who did not participate in the first trait measurement. These adolescents were neither continuing participants, nor dropouts.

${ }^{2}$ We structured the data in a mixed long-wide format, with at most 15 rows per participant. For example, the data column 'Neuroticism_year1' contained for each participant up to 15 rows of time-invariant (betweenperson) data on the first neuroticism measurement; the column 'Negative affect_year5' contained for each participant up to 15 rows of time-varying (within-person) daily negative affect data collected during the last three assessment bursts.
} 
Table 1

Number of Reports in Each Year and Number of Reports per Participant Across the Entire Study Period

\begin{tabular}{|c|c|c|c|c|c|c|c|c|c|c|c|}
\hline \multirow[b]{2}{*}{ Construct } & \multirow[b]{2}{*}{ IDs } & \multicolumn{6}{|c|}{ No. reports per year } & \multicolumn{4}{|c|}{ No. reports per participant } \\
\hline & & 2005 & 2006 & 2007 & 2008 & 2009 & 2010 & Min. & Max. & Mean & $S D$ \\
\hline Neuroticism & 1,046 & 859 & 869 & 856 & 849 & 793 & 655 & 1 & 6 & 4.67 & 1.61 \\
\hline Daily negative affect & 1,046 & 11,096 & 11,513 & 10,673 & 10,676 & 9,294 & & 15 & $80^{\mathrm{a}}$ & 50.92 & 19.61 \\
\hline Daily conflict with mother & 534 & 6,115 & 5,126 & 4,169 & 3,767 & 3,079 & & 3 & $77^{\mathrm{a}}$ & 41.68 & 19.51 \\
\hline Daily conflict with friend & 1,046 & 5,797 & 4,938 & 4,213 & 3,347 & 2,141 & & 0 & 73 & 19.54 & 15.94 \\
\hline
\end{tabular}

Note. IDs $=$ number of participants that provided reports on the construct; $2005-2010=$ number of reports provided by participants in each year; Min. $-S D=$ minimum, maximum, mean, and $S D$ of the amount of reports provided by the participants. (For example, the table shows that 859 of the 1,046 adolescents participated in the first yearly neuroticism measurement. Furthermore, the 534 adolescents who reported about daily conflicts with their mother provided at least 3 and at most 77 conflict with mother reports across the entire study period.)

${ }^{a}$ Max. $>75$ because of participation in catch-up assessment bursts, which were meant for participants with missing data.

We freely estimated the yearly within-person residual variances of negative affect and conflict and the yearly means of all variables (to allow for potential mean-level changes). Because past research has found that personality traits become more stable during adolescence (Borghuis et al., 2017; Roberts \& DelVecchio, 2000), we allowed the stability effects to change linearly over time. We imposed equality constraints on equivalent cross-lagged regression paths to ensure that we tested each cross-lagged path only once using all available data. This maximized statistical power and simplified the interpretation of the results. We also imposed equality constraints on equivalent residual variances to reduce model complexity and to ensure that we estimated only one standardized coefficient per crosslagged effect, rather than a unique standardized coefficient for each time lag because of yearly fluctuations in variance. In a subsequent sensitivity analysis, we released all equality constraints on the variables' variances to evaluate whether our results were robust against these constraints. Finally, we also explored whether cross-lagged effects changed linearly over time. We used a Bonferroni-corrected significance level equal to $\alpha=.05 / 5=.01$ (two-sided), because we tested for dynamic transactions between neuroticism and five daily experience variables.

To study the longitudinal associations between neuroticism and the five negative daily experiences variables (i.e., negative affect, conflict with mother, conflict with friend, contingency between conflict mother and negative affect, and contingency between conflict friend and negative affect), we estimated five multilevel ${ }^{3}$ random intercept cross-lagged panel models (RI-CLPM; Hamaker et al., 2015; see Figures 1 and 2). The RI-CLPMs can account for constant (i.e., time-invariant, enduring) between-person differences in daily experiences and in neuroticism (Anusic \& Schimmack, 2016; Fraley \& Roberts, 2005; Roberts, 2018) through the inclusion of (Level 3) random intercepts across the entire study period. As such, the RI-CLPMs were suited to differentiate constant between-person differences in our variables from year-specific within-persons changes therein. The Level 3 random intercepts reflected constant between-person differences (i.e., individual differences in mean levels of neuroticism and negative daily experiences across the entire study period). The yearly structured residuals $(\epsilon)$ reflected participants' year-specific deviations from their own constant level; that is, within-person residual variation not accounted for by constant between-person differences, which includes measurement error.
We modelled neuroticism as year-specific observed variables, and the daily experiences as year-specific (i.e., Level 2) latent random intercepts (Models 1-3) or random slopes (Model 4 and 5). Models 1 to 3 contained five Level 2 random intercepts that decomposed the variance of daily negative affect (Model 1; Figure 1), conflict with mother (Model 2), and conflict with friend (Model 3) per year into constant between-person variance and withinperson (residual) variance not accounted for by constant betweenperson differences. Hence, the Level 2 random intercepts reflected individual differences in participants' constant levels of daily negative affect/conflict across three consecutive assessment bursts per year. Models 4 and 5 (see Figure 2) contained five Level 2 random slopes that reflected participants' year-specific withinperson contingencies between daily relationship conflict and daily negative affect. In other words, in each year, the Level 2 random slopes reflected the extent to which daily conflicts with mother (Model 4) or friend (Model 5) were related to participants' level of negative affect on that same day. We used yearly person-mean centered negative affect and relationship conflict scores to estimate the Level 2 contingencies (Preacher et al., 2010). To ensure convergence of all models, we only included respondents who participated in at least one daily negative affect/conflict assessment across at least two different years.

To evaluate whether the differentiated RI-CLPM indeed fit our data better than the more parsimonious and widely used crosslagged panel model (CLPM), we compared the fit of both models. The CLPMs were nested in the RI-CLPMs, but the CLPMs did not contain Level 3 random intercepts that accounted for constant between-person differences. We selected the best-fitting models using the comparative fit index (CFI; values $\geq 0.95$ indicate good fit), the root mean square error of approximation (RMSEA; values $\leq 0.06$ indicate good fit), the standardized root mean residual (SRMR; values $\leq 0.08$ indicate good fit), and MLR $\chi^{2}$-difference

\footnotetext{
${ }^{3}$ Our models resembled the standard CLPM, but were different in two ways. First, our models did not contain contemporaneous residual covariances, because we measured neuroticism and daily experiences not contemporaneously but sequentially (i.e., daily experiences were assessed in-between the trait measurements). Second, because our daily diary data had a multilevel structure, we included negative daily experiences not as observed variables, but as latent variables (i.e., as Level 2 random intercepts or random slopes; see below).
} 


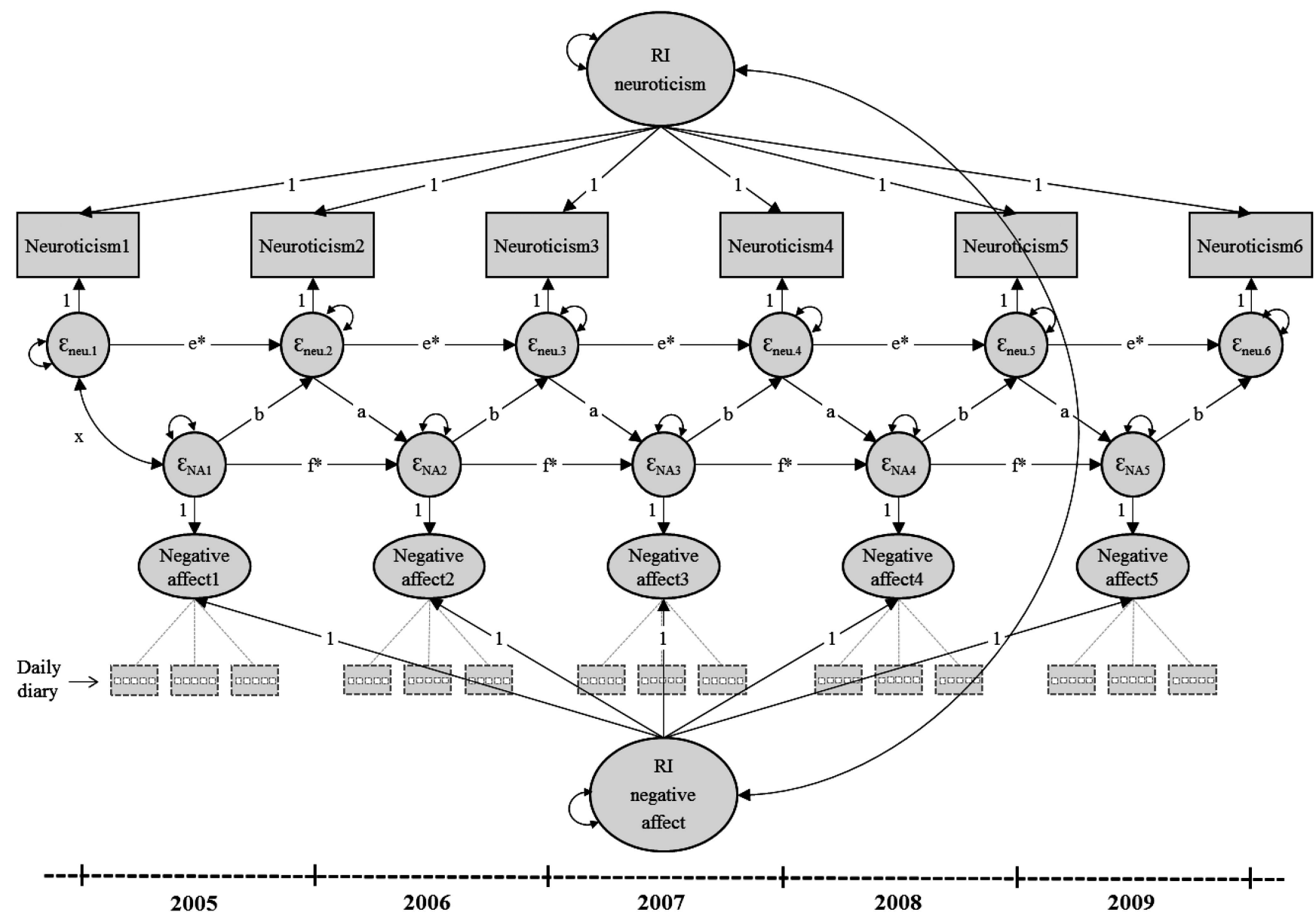

Figure 1. Multilevel random intercept cross-lagged panel models (RI-CLPM; Model 1) estimating longitudinal associations between yearly measured neuroticism and daily measured negative affect. As indicated by the dashed gray boxes, we measured daily experiences each year using three bursts of daily diary assessments that each lasted five consecutive days. Observed variables are shown in rectangles and latent variables are shown in circles. The latent 'Negative affect1-6' variables are year-specific Level 2 random intercepts, reflecting participants' average level of daily negative affect across 15 days. 'RI neuroticism' and 'RI negative affect' are Level 3 random intercepts, reflecting individual differences in constant levels of neuroticism and negative affect across the study period. We constrained path coefficients with identical letters to be equal. Paths ' $\mathrm{e}$ ", and ' $\mathrm{f}$ ", were allowed to change linearly over time.

test for nested models based on loglikelihood $(\alpha=.05 ; \mathrm{Hu} \&$ Bentler, 1999). ${ }^{4}$

\section{Results}

Table 2 shows the descriptive statistics of neuroticism and daily negative affect and relationship conflict in each year.

\section{Preliminary Analyses}

Adolescents reported more conflict with their mother $(M=$ $3.91, S E=.02)$ than with their best friend $(M=3.36, S E=.01)$. Daily negative affect was positively correlated with daily relationship conflict, both at the between-person level ( $r=.64$ for conflict with mother; $r=.56$ for conflict with friend) and at the withinperson level ( $r=.28$ for conflict with mother; $r=.21$ for conflict with friend). Daily conflict with mother was also positively cor- related with daily conflict with friend at both the between-person level $(r=.60)$ and at the within-person level $(r=.19)$. A multilevel analysis on all 75 assessment days indicated that adolescents differed substantially with respect to how strongly their level of daily negative affect was associated with their level of daily conflict with mother $\left(\beta=.17, b=0.37, S E=.02, S D_{(b)}=\right.$ $0.32)$ and their level of daily conflict with friend $(\beta=.12, b=$ $\left.0.34, S E=.02, S D_{(b)}=0.37\right)$.

\footnotetext{
${ }^{4}$ We adopted a different statistical analysis strategy in an earlier version of this manuscript. In a previous version, we conducted a two-step analysis in which we first computed mean level, variability, and contingency variables using multilevel analyses and subsequently included these as 'observed' variables in path models to test for cross-lagged associations with all Big Five personality traits. In these analyses, we found evidence for bidirectional effects. The first submitted version of this article can be found at https://osf.io/pm9th/.
} 


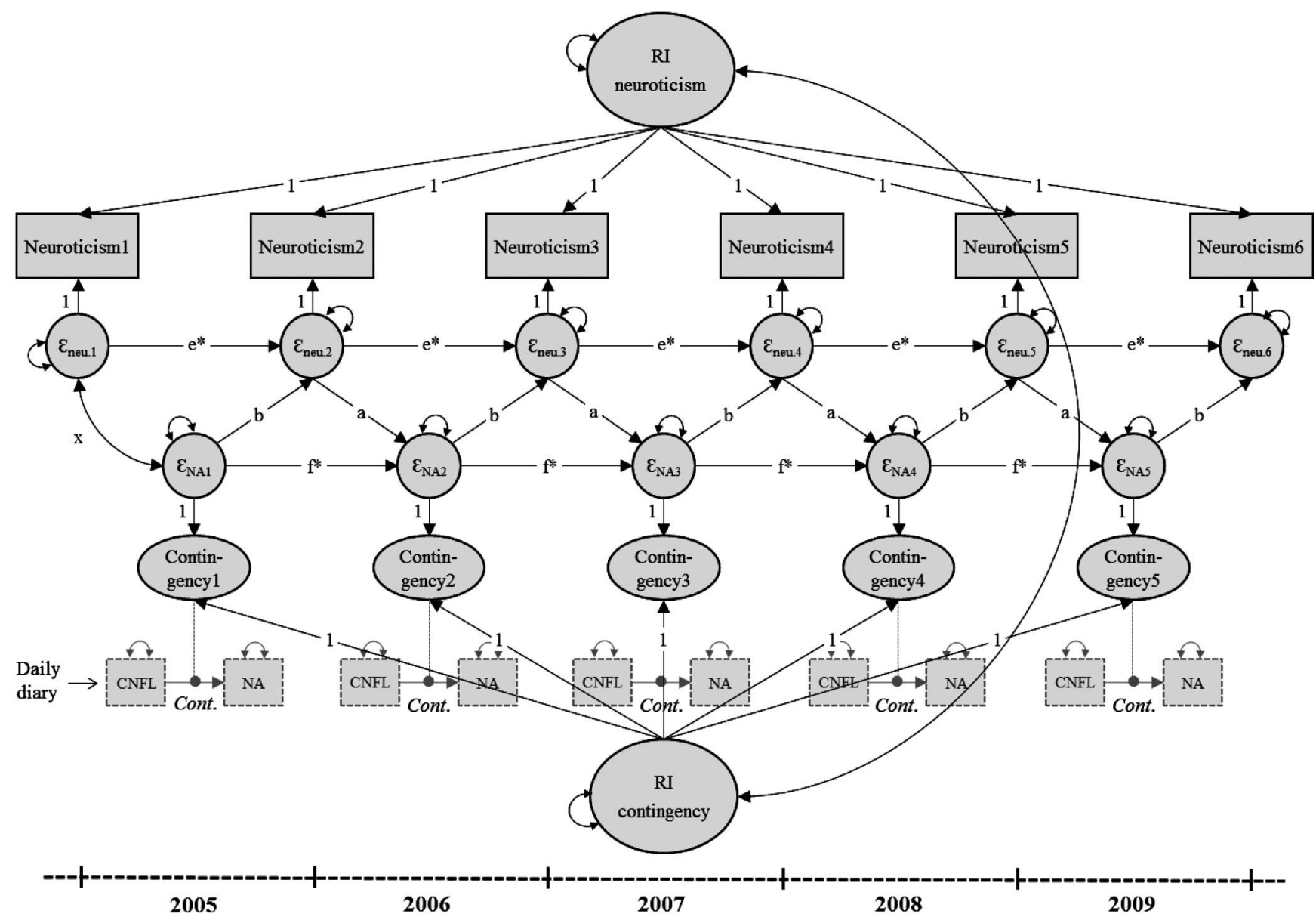

Figure 2. Multilevel random intercept cross-lagged panel models (RI-CLPM) estimating longitudinal associations between yearly measured neuroticism and yearly estimated within-person contingencies between daily negative affect (NA) and daily conflict (CNFL) with mother (Model 4) or with best friend (Model 5). The filled circles in the arrows from CNFL to NA represent random slopes, which were estimated across three assessment bursts (shown in Figure 1). The random slopes/contingencies ('Contingency1-5') reflect in each year the extent to which participants' level of daily negative affect was contingent on their level of relationship conflict on the same day. We person-mean centered negative affect and conflict in each year. See Figure 1 for more explanation.

\section{Model Selection}

To evaluate whether the differentiated RI-CLPMs fit our data better than CLPMs, we compared the fit of both models (Table 1 in the supplemental materials). The CFI and SRMR measures and the MLR $\chi^{2}$-difference tests $(d f=3, p$-values $<.001$ for all five tests) indicated that the RI-CLPMs fit the data better than the CLPMs.

We found no significant random component for the Level 3 random intercept of conflict with friend $\left(\mathrm{s}^{2}=0.25, S E=0.57\right.$, $p=.661$ ) and the Level 3 random intercept of the contingency between daily conflict with mother and negative affect $\left(\mathrm{s}^{2}=0.00\right.$, $S E=0.03, p=.970)$. This indicates that there were no constant between-person differences in these variables. Removing these random intercepts from the models by fixing their variances to 0 did not reduce model fit $\left(\chi^{2}=3.06, d f=2, p=.22\right.$; and $\chi^{2}=-0.59, d f=2, p=1$, respectively). Hence, the most parsimonious models that fit the data best were models with Level
3 random intercepts for neuroticism (Models 1-5), negative affect (Model 1), conflict with mother (Model 2), and the contingency between conflict with friend and negative affect (Model 5), but without Level 3 random intercepts for conflict with friend (Model 3 ) and the contingency between conflict with mother and negative affect (Model 4).

Table 3 shows model summary statistics of the most parsimonious, best-fitting models that we selected. The parameter estimates of the initial CLPMs and RI-CLPMs can be found in supplemental material Table 2. The Mplus output files of our selected models, which contain all model specifications and parameter estimates, can be found at https://osf.io/dsnvc.

\section{Main Results}

Associations between random intercepts. Table 4 shows a substantial positive correlation between the (Level 3) random intercepts of neuroticism and daily negative affect, indicating that 
Table 2

Descriptive Statistics

\begin{tabular}{lccccccr}
\hline \multicolumn{1}{c}{ Variable } & Year & $n$ & $M$ & $S E$ & $S D$ & Min. & Max. \\
\hline Neuroticism & 1 & 859 & 3.54 & .04 & 1.08 & 1.00 & 7.00 \\
& 2 & 869 & 3.45 & .04 & 1.17 & 1.00 & 7.00 \\
& 3 & 856 & 3.50 & .04 & 1.20 & 1.00 & 6.83 \\
Negative affect & 4 & 849 & 3.54 & .04 & 1.21 & 1.00 & 7.00 \\
& 5 & 793 & 3.52 & .04 & 1.20 & 1.00 & 7.00 \\
& 6 & 655 & 3.55 & .05 & 1.19 & 1.00 & 7.00 \\
Conflict with mother & 1 & 873 & 6.04 & .10 & 3.04 & 3.00 & 24.84 \\
& 2 & 904 & 6.62 & .12 & 3.53 & 3.00 & 22.21 \\
& 3 & 866 & 6.76 & .12 & 3.53 & 3.00 & 17.98 \\
Conflict with friend & 4 & 831 & 6.79 & .13 & 3.81 & 3.00 & 21.45 \\
& 5 & 755 & 6.68 & .13 & 3.71 & 3.00 & 19.19 \\
& 2 & 529 & 3.87 & .07 & 1.70 & 2.00 & 9.67 \\
& 3 & 469 & 4.22 & .09 & 1.96 & 2.00 & 14.00 \\
& 4 & 428 & 3.91 & .09 & 1.84 & 2.00 & 11.00 \\
& 5 & 383 & 3.97 & .10 & 1.86 & 2.00 & 12.00 \\
& 2 & 764 & 3.17 & .05 & 1.39 & 2.00 & 12.00 \\
& 3 & 661 & 3.36 & .07 & 1.69 & 2.00 & 9.83 \\
& 4 & 560 & 3.26 & .07 & 1.57 & 2.00 & 9.34 .00 \\
& 5 & 428 & 3.17 & .08 & 1.57 & 2.00 & 11.00 \\
\hline
\end{tabular}

Note. The negative affect and conflict variables were averaged across three assessment bursts per year.

overall mean levels of neuroticism were positively associated with overall mean levels of negative affect (i.e., a between-person association). Furthermore, the random intercept of neuroticism was moderately positively correlated with the random intercept of daily conflict with mother and with the random intercept of adolescents' contingency between conflict with friend and negative affect.

Stability effects. We found substantial stability effects for all measures (Table 5; see paths ' $\mathrm{e}$ "' and ' $\mathrm{f}$ ', in Figures 1 and 2). Because we accounted for constant between-person differences in neuroticism, negative affect (Model 1), conflict with mother (Model 2), and the contingency between conflict with friend and negative affect (Model 5), the stability effects of these variables can be interpreted as within-person carry-over effects, which represent the extent to which higher-than-typical values on one measurement occasion predicted higher-than-typical values on the next occasion. The within-person carry-over effect of neuroticism (Model 1) increased linearly $(p<.001)$ in magnitude across the five trait measurements, from $\beta=.15(S E=.05)$ to $\beta=.53$ $(S E=.05)$. The within-person carry-over effect of the contingency between daily conflict with friend and negative affect increased linearly $(p<.001)$ from $\beta=.75(S E=.09)$ to $\beta=1.59(S E=$ .04)..$^{5}$

The stability effects of conflict with mother (Model 3) and the contingency between conflict with mother and negative affect (Model 4) represent rank-order stability effects, because we removed the random intercepts of these variables. The rank-order stability effect of the contingency variable increased linearly $(p<$ $.001)$ from $\beta=.56(S E=.06)$ to $\beta=1.05(S E=.05)$. We found no evidence for linear changes in the stability effects of negative affect, conflict with mother, and conflict with friend.

Cross-lagged effects. We found evidence for bidirectional longitudinal effects between neuroticism and daily negative affect
(Model 1; see paths ' $a$ ' and ' $b$ ' in Figure 1). That is, higher-thantypical levels of neuroticism were preceded and followed by higher-than-typical levels of daily negative affect. We found no within-person associations between neuroticism and daily conflict with mother (Model 2), nor between neuroticism and adolescents' contingency between daily conflict with friend and daily negative affect (Model 5).

Furthermore, in the models with only one Level 3 random intercept (Models 3 and 4), we estimated longitudinal associations between yearly within-person changes in neuroticism and yearly rank-order differences in daily experiences. Within-person changes in neuroticism did not predict subsequent rank-order differences in conflict with friend and in the contingency between conflict with mother and negative affect. However, rank-order differences in conflict with friend (Model 3) and rank-order differences in adolescents' contingency between conflict with mother and negative affect (Model 4) were positively associated with subsequent within-person changes in neuroticism. In other words, adolescents who in a particular year reported relatively high levels of daily conflict with their friend, and adolescents whose contingency between their daily experiences conflict with mother and negative affect was relatively high, showed a greater increase in neuroticism than adolescents who scored low on these daily experience variables.

\section{Sensitivity Analysis: Releasing Equality Constraints on Error Variances}

We conducted a sensitivity analysis by means of rerunning Models 1 to 5 while releasing the equality constraints on the residual variances of the neuroticism variables and the daily experience variables (supplemental material Table 3). The unstandardized cross-lagged parameter estimates (paths ' $a$ ' and ' $b$ ' in Figures 1 and 2) remained similar, and the statistical inferences based on the $p$ values regarding these estimates remained identical to the results reported in Table 5 .

\section{Exploratory Analysis: Linear Change of the Cross-Lagged Effects}

Finally, we explored whether the magnitude of any of the cross-lagged effects changed during the study period. We ran Models 1 to 5 again, this time allowing both the stability effects ('e' and ' $\mathrm{f}$ ') and cross-lagged effects (' $a$ ' and ' $b$ ') to change linearly over time. Using a Bonferroni-corrected significance level equal to $\alpha=.05 / 10=.005$, we found evidence for linear change of one cross-lagged parameter: The within-person effect of daily negative affect on subsequent neuroticism decreased significantly $(p=.002)$ over time, from $b=.09(S E=.02, p<.001)$ in the first time lag to $b=.01$ ( $S E=.01, p=.26)$ in the fifth time lag. The effect was statistically significant $(p \leq .001)$ in all time lags other than the fifth.

\footnotetext{
${ }^{5}$ If standardized coefficients exceed 1 , this does not necessarily imply that the model is inaccurate (Jöreskog, 1999). Other studies have reported standardized coefficients exceeding 1 (e.g., Wrzus et al., 2017). In our case, the result might be related to the fact the random slopes were less reliable and to the linear constraint that we imposed on these stability effects to ensure model convergence.
} 
Table 3

Model Summary Statistics

\begin{tabular}{|c|c|c|c|c|c|c|c|c|c|c|}
\hline Model & Dyads & IDs & Obs. & Para. & $\chi^{2}$ & $d f$ & $p$ & $\mathrm{CFI}$ & RMSEA & SRMR \\
\hline 1. Negative affect & 550 & 1,020 & 57,690 & 30 & 131.22 & 62 & $<.001$ & .98 & .01 & .04 \\
\hline 2. Conflict with mother & - & 530 & 25,159 & 30 & 114.84 & 62 & $<.001$ & .98 & .01 & .04 \\
\hline 3. Conflict with friend & 492 & 878 & 24,298 & 28 & 116.08 & 64 & $<.001$ & .98 & .01 & .05 \\
\hline 4. Contingency (mother) & - & 530 & 56,366 & 35 & - & - & - & - & - & - \\
\hline 5. Contingency (friend) & 492 & 878 & 71,059 & 37 & - & - & - & - & - & - \\
\hline
\end{tabular}

Note. $\mathrm{CFI}=$ comparative fit index; RMSEA $=$ root-mean-square error of approximation; SRMR $=$ standardized root-mean-square residual; Dyads $=$ number of friendship dyads; IDs = number of participants; Obs. = number of daily diary and yearly trait reports; Para. = number of freely estimated parameters; CFI, RMSEA, and SRMR are model fit measures. The subsample of best friends was not included in Model 2 and Model 4 because only target adolescents reported daily conflicts with their mother. Model fit statistics were not available for models with random slopes (i.e., Models 4 and 5).

\section{Discussion}

The goal of this measurement burst study was to examine the longitudinal associations between neuroticism and daily experiences of negative affect and interpersonal problems with parents and peers during adolescence. Using RI-CLPMs, we differentiated covariance at the level of constant between-person differences from dynamic processes that occurred within persons. The most parsimonious, best-fitting models contained random intercepts indicating constant between-person differences (for the duration of the study) in neuroticism, negative affect, conflict with mother, and the contingency between conflict with friend and negative affect- but not for conflict with friend or the contingency between conflict with mother and negative affect. At the level of constant between-person differences, neuroticism was associated with more negative daily experiences. At the level of yearly within-person changes, we found bidirectional longitudinal effects between neuroticism and daily negative affect.

\section{Constant Between-Person Differences}

We found that the random intercepts that accounted for constant between-person differences in our study variables across the study period significantly improved model fit. Our evidence for constant between-person differences in neuroticism is consistent with theory (Roberts, 2018) and previous longitudinal research (Anusic \& Schimmack, 2016; Fraley \& Roberts, 2005) that indicated that personality traits are influenced by constant factors. These constant factors could reflect constancy in response styles, constancy in genetic influences, and/or constancy in environmental influences on individual differences in our measures (Briley \& Tucker-Drob, 2014; Fraley \& Roberts, 2005). In contrast, we found no evidence for constant between-person differences in daily conflict with friend and adolescents' contingency between daily conflict with mother and negative affect when constant between-person differences in neuroticism were also included in the model. This is surprising, particularly because according to the ICC1 coefficient, approximately $50 \%$ of the variance of yearly mean levels of conflict with friend was attributable to between-person differences. Most likely, our daily relationship conflict data contained too many missing values (see Table 1) and/or too few yearly waves to enable the model to accurately differentiate constant stability from temporal (i.e., rank-order) stability (Hamaker et al., 2015). These models indeed had very high year-to-year stability coefficients, which effectively functioned as a constant random intercept factor. The inclusion of additional time points is likely necessary to differentiate these two sources of personality stability (see also the limitations section below).

Consistent with previous research (Côté \& Moskowitz, 1998; Lopes et al., 2003; Mroczek \& Almeida, 2004; Wrzus et al., 2017), we found evidence for positive correlations between the constant variance of our neuroticism measure and the constant variance of our negative daily experience variables. These zero-order betweenperson correlations could be manifestations of overlapping constant genetic influences, overlapping constant environmental influences (e.g., neighborhood characteristics might have exerted constant effects on neuroticism and daily experiences), and/or overlapping influences of constant response styles. In addition, the correlations may reflect past unidirectional or bidirectional effects

Table 4

Level 3 Random Intercept Variances and Their Bivariate Associations of Models 1-5

\begin{tabular}{|c|c|c|c|c|c|c|c|c|c|c|}
\hline \multirow[b]{2}{*}{ Model } & \multicolumn{3}{|c|}{$\begin{array}{l}\text { RI daily } \\
\text { experience }\end{array}$} & \multicolumn{3}{|c|}{ RI neuroticism } & \multicolumn{4}{|c|}{$\begin{array}{l}\text { Associations } \\
\text { between RIs }\end{array}$} \\
\hline & $s^{2}$ & $S E$ & $p$ & $\mathrm{~s}^{2}$ & $S E$ & $p$ & $r$ & cov. & $S E$ & $p$ \\
\hline 1. Negative affect & 4.91 & .87 & $<.001$ & .68 & .05 & $<.001$ & .50 & .92 & .12 & $<.001$ \\
\hline 2. Conflict with mother & 1.36 & .49 & .005 & .73 & .07 & $<.001$ & .32 & .32 & .09 & $<.001$ \\
\hline 3. Conflict with friend & $-^{\mathrm{a}}$ & $-^{a}$ & $-^{a}$ & .65 & .05 & $<.001$ & $-^{a}$ & $-^{a}$ & $-^{\mathrm{a}}$ & $-^{a}$ \\
\hline 4. Contingency (mother) & $-^{\mathrm{a}}$ & $-^{\mathrm{a}}$ & $-^{\mathrm{a}}$ & .72 & .07 & $<.001$ & $-^{\mathrm{a}}$ & $-^{\mathrm{a}}$ & - $^{\mathrm{a}}$ & $\mathrm{-a}^{\mathrm{a}}$ \\
\hline 5. Contingency (friend) & .14 & .02 & $<.001$ & .68 & .05 & $<.001$ & .25 & .08 & .02 & $<.001$ \\
\hline
\end{tabular}

Note. $\quad \mathrm{RI}=$ random intercept; $\mathrm{s}^{2}=$ variance; $r=$ correlation; cov. $=$ covariance.

a Not applicable because we removed the nonsignificant Level 3 random intercepts of "conflict with friend" and "contingency (mother)" from the model. Bold coefficients: $p<.01$. 
Stability Effects, Initial Associations Between Neuroticism and Negative Daily Experiences, and Cross-Lagged Effects

\begin{tabular}{|c|c|c|c|c|c|c|c|c|c|c|c|c|c|c|}
\hline \multirow[b]{2}{*}{ Model } & \multicolumn{2}{|c|}{ Stability $^{\mathrm{b}}$} & \multicolumn{4}{|c|}{$\begin{array}{l}\text { Initial association } \\
\text { Neu. Daily exp. }\end{array}$} & \multicolumn{4}{|c|}{ Neu. $\rightarrow$ Daily exp. } & \multicolumn{4}{|c|}{ Daily exp. $\rightarrow$ Neu. } \\
\hline & $\beta$ & $S E$ & $\beta$ & $b$ & $S E$ & $p$ & $\beta$ & $b$ & $S E$ & $p$ & $\beta$ & $b$ & $S E$ & $p$ \\
\hline 1. Negative affect & .78 & .08 & .05 & .08 & .09 & .399 & .06 & .18 & .06 & .004 & .07 & .03 & .01 & .001 \\
\hline 2. Conflict with mother & .58 & .28 & .11 & .10 & .07 & .192 & .04 & .05 & .05 & .364 & .06 & .05 & .04 & .238 \\
\hline 3. Conflict with friend ${ }^{a}$ & .83 & .04 & .17 & .17 & .05 & .001 & .02 & .02 & .04 & .529 & .11 & .07 & .02 & $<.001$ \\
\hline 4. Contingency (mother) & .56 & .06 & -.14 & -.04 & .02 & .094 & .02 & .01 & .02 & .553 & .08 & .21 & .08 & .004 \\
\hline 5. Contingency (friend) & .75 & .09 & -.14 & -.01 & .02 & .652 & -.02 & .00 & .02 & .739 & .00 & .04 & .04 & .404 \\
\hline
\end{tabular}

Note. The standardized and unstandardized regression coefficients are estimates of paths ' $\mathrm{f}$ ' (Stability), ' $\mathrm{x}$ ' (Initial association Neu. $\sim$ Daily exp.), 'a' (Neu. $\rightarrow$ Daily exp.), and 'b' (Daily exp. $\rightarrow$ Neu.) of Figure 1 and Figure 2. The two contingency variables reflect individual differences in adolescents' contingency (i.e., dependency, coupling) between their level of daily relationship conflict with mother/friend and their level of daily negative affect.

a We removed the Level 3 random intercepts of "conflict with friend" and "contingency (mother)" from the model, which alters the substantive interpretation of some of the parameter estimates of these models. ${ }^{\mathrm{b}}$ All stability effects were allowed to change linearly over time. The reported coefficients refer to the stability between the first and second year. Bold coefficients: $p<.01$.

between neuroticism and negative daily experiences that were preserved across time (Roberts, 2018). For example, interpersonal problems during childhood might have had an enduring influence on adolescents' level of neuroticism and on their relationship experiences with close others. To gain more insight into the developmental processes that gave rise to constant between-person associations in adolescence, future research may extend the longitudinal study period to include childhood.

\section{Within-Person Effects Between Neuroticism and Negative Daily Experiences}

The statistically significant variance of the yearly residuals indicated that adolescents differed from each other by how they deviated each year from their own constant level. This suggested that the yearly within-person changes in neuroticism and negative daily experiences at least partly reflected changes that were not attributable to random measurement error. Consistent with predictions of both endogenous and dynamic personality theories, we found that within-person changes in neuroticism were positively associated with subsequent within-person changes in daily negative affect. This association may be explained by the small but consistent influences that increased neuroticism might have had on adolescents' affect across situations (Costa \& McCrae, 1980). For example, changes in neuroticism might have influenced adolescents' daily experiences of negative affect because high neuroticism is positively associated with affective reactivity to stressful situations (Gunthert et al., 1999; Leger et al., 2016) and the extent to which people pay attention to negative and threatening stimuli (Ormel, Bastiaansen, et al., 2013).

Notably, we also found that within-person changes in daily negative affect predicted subsequent within-person changes in neuroticism. This finding supports a key tenet of dynamic personality theories that personality traits can change gradually because of the accumulation of everyday psychological experiences (Baumert et al., 2017; Geukes, van Zalk, \& Back, 2018; Roberts, 2018; Roberts \& Jackson, 2008; Wrzus \& Roberts, 2017). Future research may shed light on the question whether this effect was driven by biological mechanisms (e.g., changes in gene expressions and neuroanatomical structures), associative mechanisms (e.g., implicit learning, reinforcement learning, and habit forma- tion), or reflective mechanisms (e.g., conscious memories about one's past states; Baumert et al., 2017; Buss \& Craik, 1983; Roberts, 2018; Wrzus \& Roberts, 2017).

The within-person effects of negative affect on neuroticism are more difficult to reconcile with the assertion of endogenous personality theories that personality traits are immune to the effects of psychological experiences (McCrae \& Costa, 2008; McCrae \& Sutin, 2018). However, in defense of endogenous theories, one could argue that people's temporary fluctuations around their constant neuroticism level are not true personality trait changes. These fluctuations may reflect temporary changes in selfperceptions, induced by past negative affect experiences, rather than enduring changes in true trait levels. We encourage scholars to explicate recommendations how to conceptualize and measure personality trait changes (for a recent example, see Roberts, 2018).

Our evidence for symmetrical, bidirectional within-person effects between neuroticism and daily experiences of negative affect is consistent with the corresponsive principle of personality development (e.g., Roberts et al., 2008). Especially during the formative period of adolescence, the corresponsive, mutually reinforcing effects between neuroticism and daily experiences of negative affect may have long-term consequences for individuals' emotional well-being (Costa \& McCrae, 1980). People who are in detrimental spirals might become increasingly neurotic, resulting in increasingly negative daily experiences, and so forth. Conversely, people who are in upward spirals might become increasingly emotionally stable, resulting in decreasing negative experiences. In addition to their theoretical value, these results may aid in designing interventions. For example, practitioners may be able to reduce adolescents' neuroticism and daily emotional difficulties by intervening in their daily experience patterns or by offering to help them to regulate their emotions. Future intervention studies may test whether such trainings indeed facilitate socially desirable decreases in neuroticism and negative affect.

We found no evidence that within-person changes in neuroticism were longitudinally associated with within-person changes of daily conflict in established relationships with close others. However, we did find that, compared with other adolescents who reported little conflict, adolescents who reported higher levels of 
daily conflict with their friend tended to show stronger subsequent within-person increases in their level of neuroticism. The lack of evidence for longitudinal effects of neuroticism on relationship conflict is inconsistent with the widely established notion that neuroticism negatively affects people's relationship experiences, for example, through negative interpretations of ambiguous relationship cues (Finn et al., 2013) and enhanced emotional reactivity to relationship problems (Suls et al., 1998). One explanation for this somewhat surprising finding is that neuroticism may be more relevant during the early stages of peer relationships (Selfhout et al., 2010) than in the development of relatively stable, wellestablished relationships that we investigated. More research is needed to gain insights into the processes through which neuroticism is associated with interpersonal problems (Branje, Van Lieshout, \& Van Aken, 2004; Kelly \& Conley, 1987; Lopes et al., 2003; Sturaro et al., 2008).

\section{Strengths and Limitations}

Important strengths of this study are that we used a statistical approach that differentiated constant between-person differences from time-specific within-person changes, and that we examined dynamic transactions during the formative and sometimes turbulent period of adolescence. In addition, we measured negative affect and interpersonal problems in daily life by means of a 5-year measurement burst design, and we used a relatively large sample of target adolescents and their friends. However, we also note some important limitations that may be addressed in future studies.

First, we cannot infer from our correlational design that the longitudinal within-person associations between neuroticism and daily negative affect reflect a causal relation. Although one benefit of our statistical approach was that the longitudinal within-person associations were controlled for all possible time-invariant covariates (Berry \& Willoughby, 2017; Hamaker et al., 2015), we cannot rule out that time-varying covariates confounded our results. For example, it is possible that the effect of negative affect on changes in neuroticism was driven by underlying biological processes (e.g., hormonal changes or epigenetic changes) or other psychological experiences (e.g., feelings of depression, loneliness, or low self-esteem) that influenced adolescents' feelings of negative affect as well as their level of neuroticism. To gain more insight into causality, future research may examine the mechanisms that drive the effects of daily experiences on personality traits (Baumert et al., 2017; Geukes et al., 2018; Wrzus \& Roberts, 2017) and use experimental designs. For example, intervention studies could test whether random assignment of participants to a control condition or a treatment condition aimed at improving people's daily affective experiences (e.g., though emotion regulation training or by repeatedly sending unexpected small gifts and complements; Ogedegbe et al., 2012) is associated with differential changes in personality traits (Sih et al., 2015).

Second, we measured daily experiences and personality traits by means of self-report questionnaires. Although self-reports do justice to the subjective nature of negative affect and interpersonal problems, they can be inconsistent with additional information sources, such as reports from informants and behavioral observations of relationship conflicts. For example, in our study, agreement between friends' reports about their level of conflict with each other was only moderate. Future research may reexamine our research questions using informant-reports and behavioral observations to investigate the extent to which constant between-person differences reflected response styles and to investigate the extent to which yearly within-person changes in neuroticism reflected meaningful personality changes.

Third, we focused on negative daily experiences and relationship experiences with mother and best friend during the period of adolescence. Future research may provide more insight into the boundary conditions of dynamic state-trait transactions by also focusing on positive daily experiences (e.g., do positive affective and interpersonal experiences also predict changes in neuroticism?; Soto, 2015), on other social relationships (e.g., do interpersonal problems with a father, sibling, and romantic partner also predict changes in neuroticism?), and on other periods (e.g., childhood and young adulthood). For example, interpersonal problems with a best friend and parent may have a smaller impact on neuroticism in adulthood than in adolescence because in adulthood these relationships may be more stable and conflicts in these relationships may pose a lower threat to individuals' access to resources, their social status, and their need to belong (Reitz, Zimmermann, Hutteman, Specht, \& Neyer, 2014).

Fourth, we used within-person contingencies between interpersonal problems and negative affect as an indicator of adolescents' affective reactivity to interpersonal problems. However, the reliability and validity of this indicator was limited because some participants showed little variance in their daily experiences over time (that hampers the estimation of covariation), because the random slopes were estimated based on relatively few data points, and because we estimated the contingencies not lagged but concurrently (i.e., conflict on day $t$ predicted negative affect on day $t$ rather than on day $t+1$ ). To address these concerns, future research may use experience sampling to estimate contingencies based on multiple data points per day (e.g., Wrzus et al., 2017).

Fifth, despite our relatively large sample size and the frequent measurement of neuroticism and daily experiences, we experienced some modeling issues that might be alleviated by including additional waves of data. For example, some of the Level 3 random intercepts had no significant random component, and in the contingency models, some of the standardized stability coefficients exceeded 1 . For some models, we solved convergence issues by using starting values and removing participants with many missing data points. While this is not problematic per se, it does suggest the need for future studies to replicate our results.

Finally, a comparison between the yearly Cronbach's $\alpha$ values of the neuroticism measure and the yearly ICC2 coefficients of the daily negative affect measure suggested that the Level 2 random intercepts of negative affect were more reliable than the measurements of neuroticism. Therefore, the regression coefficients of neuroticism and negative affect should be compared with caution. Future research using larger samples may use more complex statistical models that include a measurement model to account for measurement error. 


\section{Conclusions}

A large body of research has established that trait neuroticism is positively associated with emotional and interpersonal problems. The present study replicated these well-established betweenperson correlations. However, our aim was to move beyond previous findings at the between-person level by also investigating how changes in neuroticism and changes in negative daily experiences were related within persons over time. Using RI-CLPMs, we found evidence for bidirectional within-person effects between neuroticism and daily experiences of negative affect. The withinperson effect of daily negative affect on neuroticism is consistent with dynamic theories of personality development. However, this finding is difficult to reconcile with the position of endogenous personality theories that personality traits are immune to the effects of psychological experiences.

The use of RI-CLPM helped to gain a deeper understanding of the associations between neuroticism and negative daily experiences during adolescence. Model fit measures suggested that, compared with the CLPM, the RI-CLPM provided a better representation of the underlying processes that gave rise to the data. This finding is consistent with theory and previous research suggesting that personality traits partly reflect constant betweenperson differences (Fraley \& Roberts, 2005; Roberts, 2018). The cross-lagged estimates of the RI-CLPMs were better representations of within-person processes than the cross-lagged estimates of the CLPMs. Corroborating results from simulation studies (Berry \& Willoughby, 2017; Hamaker et al., 2015), we found that the CLPMs sometimes revealed significant effects that were not present at the within-person level (see supplemental material Table 3). We encourage future researchers to apply models that differentiate between constant between-person differences from temporary within-person changes.

\section{References}

Adachi, P., \& Willoughby, T. (2015). Interpreting effect sizes when controlling for stability effects in longitudinal autoregressive models: Implications for psychological science. European Journal of Developmental Psychology, 12, 116-128. http://dx.doi.org/10.1080/17405629.2014 .963549

Allemand, M., Hill, P. L., \& Lehmann, R. (2015). Divorce and personality development across middle adulthood. Personal Relationships, 22, 122137. http://dx.doi.org/10.1111/pere.12067

Anusic, I., \& Schimmack, U. (2016). Stability and change of personality traits, self-esteem, and well-being: Introducing the meta-analytic stability and change model of retest correlations. Journal of Personality and Social Psychology, 110, 766-781. http://dx.doi.org/10.1037/ pspp0000066

Arnett, J. J. (1999). Adolescent storm and stress, reconsidered. American Psychologist, 54, 317-326. http://dx.doi.org/10.1037/0003-066X.54.5 .317

Asendorpf, J. B., \& Wilpers, S. (1998). Personality effects on social relationships. Journal of Personality and Social Psychology, 74, 15311544. http://dx.doi.org/10.1037/0022-3514.74.6.1531

Baltes, P. B., \& Nesselroade, J. R. (1979). History and rationale of longitudinal research. In J. R. Nesselroade \& P. B. Baltes (Eds.), Longitudinal research in the study of behavior and development (pp. 1-39). New York, NY: Academic.

Baumert, A., Schmitt, M., Perugini, M., Johnson, W., Blum, G., Borkenau, P., . . Wrzus, C. (2017). Integrating personality structure, personality process, and personality development. European Journal of Personality, 31, 503-528. http://dx.doi.org/10.1002/per.2115

Berry, D., \& Willoughby, M. T. (2017). On the practical interpretability of cross-lagged panel models: Rethinking a developmental workhorse. Child Development, 88, 1186-1206. http://dx.doi.org/10.1111/cdev .12660

Blakemore, S.-J. (2008). The social brain in adolescence. Nature Reviews Neuroscience, 9, 267-277. http://dx.doi.org/10.1038/nrn2353

Bleidorn, W., \& Hopwood, C. J. (in press). Stability and change in personality traits over the lifespan. In D. McAdams, R. L. Shiner, \& J. L. Tackett (Eds.), Handbook of Personality Development. New York, NY: Guilford.

Bleidorn, W., Hopwood, C. J., \& Lucas, R. E. (2018). Life events and personality trait change. Journal of Personality, 86, 83-96. http://dx.doi .org/10.1111/jopy.12286

Borghuis, J., Denissen, J. J. A., Oberski, D., Sijtsma, K., Meeus, W. H. J., Branje, S., . . . Bleidorn, W. (2017). Big Five personality stability, change, and codevelopment across adolescence and early adulthood. Journal of Personality and Social Psychology, 113, 641-657. http://dx .doi.org/10.1037/pspp0000138

Branje, S. J. T., van Lieshout, C. F. M., \& van Aken, M. A. G. (2004). Relations between Big Five personality characteristics and perceived support in adolescents' families. Journal of Personality and Social Psychology, 86, 615-628. http://dx.doi.org/10.1037/0022-3514.86.4 .615

Briley, D. A., \& Tucker-Drob, E. M. (2014). Genetic and environmental continuity in personality development: A meta-analysis. Psychological Bulletin, 140, 1303-1331. http://dx.doi.org/10.1037/a0037091

Buss, D. M., \& Craik, K. H. (1983). The act frequency approach to personality. Psychological Review, 90, 105-126. http://dx.doi.org/10 .1037/0033-295X.90.2.105

Casey, B. J., Jones, R. M., \& Hare, T. A. (2008). The adolescent brain. Annals of the New York Academy of Sciences, 1124, 111-126. http://dx .doi.org/10.1196/annals. 1440.010

Ching, C. M., Church, A. T., Katigbak, M. S., Reyes, J. A. S., TanakaMatsumi, J., Takaoka, S., . . . Ortiz, F. A. (2014). The manifestation of traits in everyday behavior and affect: A five-culture study. Journal of Research in Personality, 48, 1-16. http://dx.doi.org/10.1016/j.jrp.2013 .10 .002

Costa, P. T., Jr., \& McCrae, R. R. (1980). Influence of extraversion and neuroticism on subjective well-being: Happy and unhappy people. Journal of Personality and Social Psychology, 38, 668-678. http://dx.doi .org/10.1037/0022-3514.38.4.668

Côté, S., \& Moskowitz, D. S. (1998). On the dynamic covariation between interpersonal behavior and affect: Prediction from neuroticism, extraversion, and agreeableness. Journal of Personality and Social Psychology, 75, 1032-1046. http://dx.doi.org/10.1037/0022-3514.75.4.1032

Creemers, H. E., Buil, J. M., van Lier, P. A. C., Keijsers, L., Meeus, W., Koot, H. M., \& Huizink, A. C. (2015). Early onset of cannabis use: Does personality modify the relation with changes in perceived parental involvement? Drug and Alcohol Dependence, 146, 61-67. http://dx.doi .org/10.1016/j.drugalcdep.2014.11.004

Crocetti, E., Branje, S., Rubini, M., Koot, H. M., \& Meeus, W. (2017). Identity processes and parent-child and sibling relationships in adolescence: A five-wave multi-informant longitudinal study. Child Development, 88, 210-228. http://dx.doi.org/10.1111/cdev.12547

Cronbach, L. J. (1951). Coefficient alpha and the internal structure of tests. Psychometrika, 16, 297-334. http://dx.doi.org/10.1007/BF02310555

Cuijpers, P., Smit, F., Penninx, B. W., de Graaf, R., ten Have, M., \& Beekman, A. T. (2010). Economic costs of neuroticism: A populationbased study. Archives of General Psychiatry, 67, 1086-1093. http://dx .doi.org/10.1001/archgenpsychiatry.2010.130

Denissen, J. J. A., Luhmann, M., Chung, J. M., \& Bleidorn, W. (2018). Transactions between life events and personality traits across the adult 
lifespan. Journal of Personality and Social Psychology. Advance online publication. http://dx.doi.org/10.1037/pspp0000196

Denissen, J. J. A., \& Penke, L. (2008). Motivational individual reaction norms underlying the Five-Factor model of personality: First steps towards a theory-based conceptual framework. Journal of Research in Personality, 42, 1285-1302. http://dx.doi.org/10.1016/j.jrp.2008.04.002 Ellis, B. J., Del Giudice, M., Dishion, T. J., Figueredo, A. J., Gray, P., Griskevicius, V., . . W Wilson, D. S. (2012). The evolutionary basis of risky adolescent behavior: Implications for science, policy, and practice. Developmental Psychology, 48, 598-623. http://dx.doi.org/10.1037/ a0026220

Endler, N. S., \& Parker, J. D. A. (1992). Interactionism revisited: Reflections on the continuing crisis in the personality area. European Journal of Personality, 6, 177-198. http://dx.doi.org/10.1002/per.2410060302

Evans, B. E., Stam, J., Huizink, A. C., Willemen, A. M., Westenberg, P. M., Branje, S., . . . van Lier, P. A. C. (2016). Neuroticism and extraversion in relation to physiological stress reactivity during adolescence. Biological Psychology, 117, 67-79. http://dx.doi.org/10.1016/j .biopsycho.2016.03.002

Finn, C., Mitte, K., \& Neyer, F. J. (2013). The relationship-specific interpretation bias mediates the link between neuroticism and satisfaction in couples. European Journal of Personality, 27, 200-212. http:// dx.doi.org/10.1002/per.1862

Fleeson, W., \& Jolley, S. (2006). A proposed theory of the adult development of intraindividual variability in trait-manifesting behavior. In D. K. Mroczek \& T. D. Little (Eds.), Handbook of personality development (pp. 41-59). Mahwah, NJ: Erlbaum Publishers.

Fraley, R. C., \& Roberts, B. W. (2005). Patterns of continuity: A dynamic model for conceptualizing the stability of individual differences in psychological constructs across the life course. Psychological Review, 112, 60-74. http://dx.doi.org/10.1037/0033-295X.112.1.60

Furman, W., \& Buhrmester, D. (1985). Children's perceptions of the personal relationships in their social networks. Developmental Psychology, 21, 1016-1024. http://dx.doi.org/10.1037/0012-1649.21.6.1016

Geukes, K., Nestler, S., Hutteman, R., Dufner, M., Küfner, A. C. P., Egloff, B., , . Back, M. D. (2017). Puffed-up but shaky selves: State self-esteem level and variability in narcissists. Journal of Personality and Social Psychology, 112, 769-786. http://dx.doi.org/10.1037/pspp0000093

Geukes, K., van Zalk, M., \& Back, M. D. (2018). Understanding personality development: An integrative state process model. International Journal of Behavioral Development, 42, 43-51. http://dx.doi.org/10 $.1177 / 0165025416677847$

Göllner, R., Roberts, B. W., Damian, R. I., Lüdtke, O., Jonkmann, K., \& Trautwein, U. (2017). Whose "storm and stress" is it? Parent and child reports of personality development in the transition to early adolescence. Journal of Personality, 85, 376-387. http://dx.doi.org/10.1111/jopy .12246

Gunthert, K. C., Cohen, L. H., \& Armeli, S. (1999). The role of neuroticism in daily stress and coping. Journal of Personality and Social Psychology, 77, 1087-1100. http://dx.doi.org/10.1037/0022-3514.77.5.1087

Hadiwijaya, H., Klimstra, T. A., Vermunt, J. K., Branje, S. J. T., \& Meeus, W. H. J. (2017). On the development of harmony, turbulence, and independence in parent-adolescent relationships: A five-wave longitudinal study. Journal of Youth and Adolescence, 46, 1772-1788. http:// dx.doi.org/10.1007/s10964-016-0627-7

Hallquist, M. N., \& Wiley, J. F. (2018). MplusAutomation: An R Package for Facilitating Large-Scale Latent Variable Analyses in Mplus. Structural Equation Modeling: A Multidisciplinary Journal, 25, 621-638. http://dx.doi.org/10.1080/10705511.2017.1402334

Hamaker, E. L., Kuiper, R. M., \& Grasman, R. P. P. P. (2015). A critique of the cross-lagged panel model. Psychological Methods, 20, 102-116. http://dx.doi.org/10.1037/a0038889

Hawk, S. T., Keijsers, L., Branje, S. J. T., Graaff, J. V., Wied, M., \& Meeus, W. (2013). Examining the Interpersonal Reactivity Index (IRI) among early and late adolescents and their mothers. Journal of Personality Assessment, 95, 96-106. http://dx.doi.org/10.1080/00223891.2012 .696080

Hawley, P. H., Little, T. D., \& Card, N. A. (2007). The allure of a mean friend: Relationship quality and processes of aggressive adolescents with prosocial skills. International Journal of Behavioral Development, 31, 170-180. http://dx.doi.org/10.1177/0165025407074630

Hoeksma, J. B., Sep, S. M., Vester, F. C., Groot, P. F. C., Sijmons, R., \& De Vries, J. (2000). The electronic mood device: Design, construction, and application. Behavior Research Methods, Instruments, \& Computers, 32, 322-326. http://dx.doi.org/10.3758/BF03207801

Hu, L., \& Bentler, P. M. (1999). Cutoff criteria for fit indexes in covariance structure analysis: Conventional criteria versus new alternatives. Structural Equation Modeling, 6, 1-55. http://dx.doi.org/10.1080/ 10705519909540118

Hudson, N. W., \& Fraley, R. C. (2016). Do people's desires to change their personality traits vary with age? An examination of trait change goals across adulthood. Social Psychological and Personality Science, 7, 847-856. http://dx.doi.org/10.1177/1948550616657598

Jeronimus, B. F., Ormel, J., Aleman, A., Penninx, B. W. J. H., \& Riese, H. (2013). Negative and positive life events are associated with small but lasting change in neuroticism. Psychological Medicine, 43, 2403-2415. http://dx.doi.org/10.1017/S0033291713000159

Jeronimus, B. F., Riese, H., Sanderman, R., \& Ormel, J. (2014). Mutual reinforcement between neuroticism and life experiences: A five-wave, 16-year study to test reciprocal causation. Journal of Personality and Social Psychology, 107, 751-764. http://dx.doi.org/10.1037/a0037009

John, O. P., Naumann, L. P., \& Soto, C. J. (2008). Paradigm shift to the integrative big-five trait taxonomy: History, measurement, and conceptual issues. In R. Hogan, J. Johnson, \& S. Briggs (Eds.), Handbook of personality: Theory and research (pp. 114-158). San Diego, CA: Academic Press.

Jöreskog, K. G. (1999). How large can a standardized coefficient be? Retrieved from http://www.ssicentral.com/lisrel/techdocs/How LargeCanaStandardizedCoefficientbe.pdf

Kandler, C., Bleidorn, W., Riemann, R., Angleitner, A., \& Spinath, F. M (2012). Life events as environmental States and genetic traits and the role of personality: A longitudinal twin study. Behavior Genetics, 42, 57-72. http://dx.doi.org/10.1007/s10519-011-9491-0

Karney, B. R., \& Bradbury, T. N. (1995). The longitudinal course of marital quality and stability: A review of theory, method, and research Psychological Bulletin, 118, 3-34. http://dx.doi.org/10.1037/0033-2909 .118 .1 .3

Keijsers, L., Branje, S., Hawk, S. T., Schwartz, S. J., Frijns, T., Koot, H. M., . . . Meeus, W. (2012). Forbidden friends as forbidden fruit: Parental supervision of friendships, contact with deviant peers, and adolescent delinquency. Child Development, 83, 651-666.

Kelly, E. L., \& Conley, J. J. (1987). Personality and compatibility: A prospective analysis of marital stability and marital satisfaction. Journal of Personality and Social Psychology, 52, 27-40. http://dx.doi.org/10 .1037/0022-3514.52.1.27

Koepke, S., \& Denissen, J. J. A. (2012). Dynamics of identity development and separation-individuation in parent-child relationships during adolescence and emerging adulthood - A conceptual integration. Developmental Review, 32, 67-88. http://dx.doi.org/10.1016/j.dr.2012.01.001

Lahey, B. B. (2009). Public Health significance of neuroticism. The American Psychologist, 64, 241-256. http://dx.doi.org/10.1037/a0015309;10 .1037/a0015309

Leger, K. A., Charles, S. T., Turiano, N. A., \& Almeida, D. M. (2016). Personality and stressor-related affect. Journal of Personality and Social Psychology, 111, 917-928. http://dx.doi.org/10.1037/pspp0000083

Lopes, P. N., Salovey, P., \& Straus, R. (2003). Emotional intelligence, personality, and the perceived quality of social relationships. Personality 
and Individual Differences, 35, 641-658. http://dx.doi.org/10.1016/ s0191-8869(02)00242-8

Maciejewski, D. F., van Lier, P. A. C., Branje, S. J. T., Meeus, W. H. J., \& Koot, H. M. (2017). A daily diary study on adolescent emotional experiences: Measurement invariance and developmental trajectories. Psychological Assessment, 29, 35-49. http://dx.doi.org/10.1037/ pas0000312

Magnusson, D. (1990). Personality development from an interactional perspective. In L. Pervin (Ed.), Handbook of personality: Theory and 1 research (pp. 193-222). New York, NY: Guilford Press.

McCrae, R. R., \& Costa, P. T. (2008). The Five Factor Theory of personality. In O. P. John, R. W. Robins, \& L. A. Pervin (Eds.), Handbook of Personality: Theory and Research (pp. 159-181). New York, NY: Guilford Press.

McCrae, R. R., \& Sutin, A. R. (2018). A five-factor theory perspective on causal analysis. European Journal of Personality, 32, 151-166. http:// dx.doi.org/10.1002/per.2134

Mercer, N., Keijsers, L., Crocetti, E., Branje, S., \& Meeus, W. (2016). Adolescent abstention from delinquency: Examining the mediating role of time spent with (delinquent) peers. Journal of Research on Adolescence, 26, 947-962. http://dx.doi.org/10.1111/jora.12246

Mroczek, D. K., \& Almeida, D. M. (2004). The effect of daily stress, personality, and age on daily negative affect. Journal of Personality, 72, 355-378. http://dx.doi.org/10.1111/j.0022-3506.2004.00265.x

Mund, M., \& Neyer, F. J. (2014). Treating personality-relationship transactions with respect: Narrow facets, advanced models, and extended time frames. Journal of Personality and Social Psychology, 107, 352368. http://dx.doi.org/10.1037/a0036719

Muthén, L., \& Muthén, B. (1998). Mplus user's guide (7th ed.). Los Angeles, CA: Author.

Neumann, A., van Lier, P. A. C., Frijns, T., Meeus, W., \& Koot, H. M. (2011). Emotional dynamics in the development of early adolescent psychopathology: A one-year longitudinal study. Journal of Abnormal Child Psychology, 39, 657-669. http://dx.doi.org/10.1007/s10802-0119509-3

Ogedegbe, G. O., Boutin-Foster, C., Wells, M. T., Allegrante, J. P., Isen, A. M., Jobe, J. B., \& Charlson, M. E. (2012). A randomized controlled trial of positive-affect intervention and medication adherence in hypertensive African Americans. Archives of Internal Medicine, 172, 322326. http://dx.doi.org/10.1001/archinternmed.2011.1307

Ormel, J., Bastiaansen, A., Riese, H., Bos, E. H., Servaas, M., Ellenbogen, M., . . . Aleman, A. (2013). The biological and psychological basis of neuroticism: Current status and future directions. Neuroscience and Biobehavioral Reviews, 37, 59-72.

Ormel, J., Jeronimus, B. F., Kotov, R., Riese, H., Bos, E. H., Hankin, B., ... Oldehinkel, A. J. (2013). Neuroticism and common mental disorders: Meaning and utility of a complex relationship. Clinical Psychology Review, 33, 686-697. http://dx.doi.org/10.1016/j.cpr.2013.04.003

Preacher, K. J., Zyphur, M. J., \& Zhang, Z. (2010). A general multilevel SEM framework for assessing multilevel mediation. Psychological Methods, 15, 209-233. http://dx.doi.org/10.1037/a0020141

R Core Team. (2017). R: A language and environment for statistical computing. Vienna, Austria: R Foundation for Statistical Computing.

Reitz, A. K., Zimmermann, J., Hutteman, R., Specht, J., \& Neyer, F. J. (2014). How peers make a difference: The role of peer groups and peer relationships in personality development. European Journal of Personality, 28, 279-288. http://dx.doi.org/10.1002/per.1965

Revelle, W. (2017). psych: Procedures for personality and psychological research. $R$ Package. Retrieved from http://personality-project.org/r/ psych-manual.pdf

Riese, H., Snieder, H., Jeronimus, B. F., Korhonen, T., Rose, R. J., Kaprio, J., \& Ormel, J. (2014). Timing of stressful life events affects stability and change of neuroticism. European Journal of Personality, 28, 193-200. http://dx.doi.org/10.1002/per.1929
Roberts, B. W. (2018). A revised sociogenomic model of personality traits. Journal of Personality, 86, 23-35. http://dx.doi.org/10.1111/jopy.12323

Roberts, B. W., \& DelVecchio, W. F. (2000). The rank-order consistency of personality traits from childhood to old age: A quantitative review of longitudinal studies. Psychological Bulletin, 126, 3-25. http://dx.doi .org/10.1037/0033-2909.126.1.3

Roberts, B. W., \& Jackson, J. J. (2008). Sociogenomic personality psychology. Journal of Personality, 76, 1523-1544. http://dx.doi.org/10 1111/j.1467-6494.2008.00530.x

Roberts, B. W., Wood, D., \& Caspi, A. (2008). Development of personality traits in adulthood. In O. P. John, R. W. Robins, \& L. A. Pervin (Eds.), Handbook of personality: Theory and research (pp. 375-398). New York, NY: Guilford Press.

Salemink, E., van Lier, P. A. C., Meeus, W., Raaijmakers, S. F., \& Wiers, R. W. (2015). Implicit alcohol-relaxation associations in frequently drinking adolescents with high levels of neuroticism. Addictive Behaviors, 45, 8-13. http://dx.doi.org/10.1016/j.addbeh.2015.01.002

Selfhout, M., Burk, W., Branje, S., Denissen, J., van Aken, M., \& Meeus, W. (2010). Emerging late adolescent friendship networks and Big Five personality traits: A social network approach. Journal of Personality, 78 509-538. http://dx.doi.org/10.1111/j.1467-6494.2010.00625.x

Sih, A., Mathot, K. J., Moirón, M., Montiglio, P.-O., Wolf, M., \& Dingemanse, N. J. (2015). Animal personality and state-behaviour feedbacks A review and guide for empiricists. Trends in Ecology \& Evolution, 30, 50-60. http://dx.doi.org/10.1016/j.tree.2014.11.004

Soto, C. J. (2015). Is happiness good for your personality? Concurrent and prospective relations of the Big Five with subjective well-being. Journal of Personality, 83, 45-55. http://dx.doi.org/10.1111/jopy.12081

Soto, C. J. (2016). The Little Six personality dimensions from early childhood to early adulthood: Mean-level age and gender differences in parents' reports. Journal of Personality, 84, 409-422. http://dx.doi.org/ 10.1111/jopy. 12168

Soto, C. J., \& Tackett, J. L. (2015). Personality traits in childhood and adolescence: Structure, development, and outcomes. Current Directions in Psychological Science, 24, 358-362. http://dx.doi.org/10.1177/ 0963721415589345

Specht, J., Egloff, B., \& Schmukle, S. C. (2011). Stability and change of personality across the life course: The impact of age and major life events on mean-level and rank-order stability of the Big Five. Journal of Personality and Social Psychology, 101, 862-882. http://dx.doi.org/10 .1037/a0024950

Sturaro, C., Denissen, J. J. A., Van Aken, M. A. G., \& Asendorpf, J. B. (2008). Person-environment transactions during emerging adulthood: The interplay between personality characteristics and social relationships. European Psychologist, 13, 1-11. http://dx.doi.org/10.1027/10169040.13.1.1

Suls, J., \& Martin, R. (2005). The daily life of the garden-variety neurotic: Reactivity, stressor exposure, mood spillover, and maladaptive coping. Journal of Personality, 73, 1485-1510. http://dx.doi.org/10.1111/j .1467-6494.2005.00356.x

Suls, J., Martin, R., \& David, J. P. (1998). Person-environment fit and its limits: Agreeableness, neuroticism, and emotional reactivity to interpersonal conflict. Personality and Social Psychology Bulletin, 24, 88-98. http://dx.doi.org/10.1177/0146167298241007

Van Doorn, M. D., Branje, S. J. T., Hox, J. J., \& Meeus, W. H. J. (2009). Intraindividual variability in adolescents' perceived relationship satisfaction: The role of daily conflict. Journal of Youth and Adolescence, 38, 790-803. http://dx.doi.org/10.1007/s10964-008-9308-5

Van Lier, P. A. C., Frijns, T., Neumann, A., Den Exter Blokland, E., Koot, H. M., \& Meeus, W. H. J. (2011). The RADAR young study: Design, description of sample, and validation of cohort assignment. Unpublished manuscript. 
Vermulst, A. A., \& Gerris, J. R. M. (2005). QBF: Quick Big Five persoonlijkheidstest handleiding [Quick Big Five personality test manual]. Leeuwarden, the Netherlands: LDC Publications.

Vollrath, M. (2000). Personality and hassles among university students: A three-year longitudinal study. European Journal of Personality, 14, 199-215. http://dx.doi.org/10.1002/1099-0984(200005/06)14: 3\%3C199::aid-per372\%3E3.0.co;2-b

Weisfeld, G. E. (1999). Evolutionary principles of human adolescence. New York, NY: Basic books.

Wrzus, C., Luong, G., Wagner, J., \& Riediger, M. (2017). Increases in short-term affective reactivity to daily hassles predict increases in neuroticism over six years. Manuscript submitted for publication.

Wrzus, C., \& Neyer, F. J. (2016). Co-development of personality and friendships across the lifespan. European Psychologist, 21, 254-273. http://dx.doi.org/10.1027/1016-9040/a000277

Wrzus, C., \& Roberts, B. W. (2017). Processes of personality development in adulthood: The TESSERA framework. Personality and
Social Psychology Review, 21, 253-277. http://dx.doi.org/10.1177/ 1088868316652279

Wrzus, C., Zimmermann, J., Mund, M., \& Neyer, F. J. (2016). Friendships in young and middle adulthood: Normative patterns and personality differences. In M. Hojjat \& A. Moyer (Eds.), Psychology of friendship. New York, NY: Oxford University Press. http://dx.doi.org/10.1093/ acprof:oso/9780190222024.003.0002

Yu, R., Branje, S., Keijsers, L., Koot, H. M., \& Meeus, W. (2013). Pals, problems, and personality: The moderating role of personality in the longitudinal association between adolescents' and best friends' delinquency. Journal of Personality, 81, 499-509. http://dx.doi.org/10.1111/ jopy. 12027

Received January 25, 2018

Revision received October 2, 2018

Accepted October 13, 2018

\section{E-Mail Notification of Your Latest Issue Online!}

Would you like to know when the next issue of your favorite APA journal will be available online? This service is now available to you. Sign up at https://my.apa.org/portal/alerts/ and you will be notified by e-mail when issues of interest to you become available! 